\title{
The Development Process of Human History: Guo Moruo's Historical Thoughts
}

\author{
Xiangyun Xie \\ Academy of Arts \& Design, Sichuan University of Arts and Science, Dazhou, China \\ Email: 2804351673@qq.com
}

How to cite this paper: Xie, X. Y. (2021). The Development Process of Human History: Guo Moruo's Historical Thoughts. Voice of the Publisher, 7, 56-62. https://doi.org/10.4236/vp.2021.71005

Received: February 17, 2021

Accepted: March 14, 2021

Published: March 17, 2021

Copyright ( 2021 by author(s) and Scientific Research Publishing Inc. This work is licensed under the Creative Commons Attribution International License (CC BY 4.0).

http://creativecommons.org/licenses/by/4.0/

\begin{abstract}
Marx divides the development of human history into a syllogism of selfdevelopment and a five-stage theory of social development, both of which are the internal and external manifestations of the same process of human development history. In this regard, Guo Moruo's historical thoughts point to the development process of human history with his focus on the level of awakening of conscious individuals as "humans" in real social relations, so that men can ultimately realize the ideal of leading a free life "as one wishes".
\end{abstract}

\section{Keywords}

Guo Moruo, Historical Thoughts, Human Development Process

\section{Introduction}

Marx puts forward that the first premise of all human history undoubtedly is that the existence of living individuals and the nature of human beings are not only abstracts inherent in a single person, but in reality, it is the theory regarding the sum of all social relations. Based on this, he divides the history of human development into three stages: natural person, social person, and free person, and he divides the history of human social development into five stages: primitive society, slave society, feudal society, capitalist society, and communist society. Marx regards the degree of freedom of living individuals in real social relations as the starting point and goal of studying human as well as the development of human society. Such thinking mode is essentially consistent with the ancient Chinese pursuit of the ideal of "following one's heart". Guo Moruo keenly captured this theory and applied it to the study of Chinese history. $\mathrm{He}$ pointed out that the development of Chinese society had experienced primitive society, slavery and feudalism, which was completely consistent with the social 
development stages proposed by Marxism. This has become common sense; people who criticized the previous field archaeology generally lacked knowledge of the history of social development, and some people did not believe in the stage division of the history of social development at all, so they did not pay attention to these historical materials, or were solely concentrated in the contest between the scales of the utensils, or the so-called "Yin calendar" based on the later calendars. This practice can actually be said to be begging with a golden bowl in hand (Guo, 1984a). At the time when Guo Moruo criticized the old historians and analyzed the social system of the Yin Dynasty, he mostly paid attention to the textual research and contest of ancient artifacts without noticing the changes taken place to people in real life at that time.

\section{The Division of Human Society Development Stages Is Based on the Degree of Human Liberation}

Guo Moruo repeatedly expressed that "it is an indisputable fact that in its history, China experienced primitive social system, slavery, and feudal system all the way to this stage". This idea was born out of considerations of the productivity level, changes in production relations and methods, improvements in production tools, changes in major producers, general production conditions in society, the emancipation of industry and commerce, ideological reflections, and many other aspects; it details the connections and differences of patriarchy, slavery, and feudalism. He emphasized the distinction between slavery and feudal system, in addition to the feudal system of production relations, landlord system, domestic servants and philistines became free laborers, agricultural production is no longer slavery, and industry and commerce partially abandoned slaves. The system and slave owners could not arbitrarily slaughter private slaves, they explained from the general production situation, the emancipation of industry and commerce, and ideological reflections (Guo, 1984a). In the three chapters followed, he accounted in detail and analyzed them specifically, and he concluded that the lower limit of slavery was at the turn of the Spring and Autumn Period and the Warring States Period. He analyzed the characteristics, boundaries and causes of the various stages of Chinese social development based on the principles of Marxism, representing his concerns about the inherent unity between the liberation of human survival and the level of spiritual and material life that met its own survival in the real society. This kind of thinking was fully reflected in his analysis of the basis and characteristics of the dividing point between China's slave society and feudal society. Such mode of thinking essentially reflects Chinese people's self-consciousness, which is consistent with ancient Chinese people's pursuit and ideal of following one's heart. It is also out of this fundamental reason that Marxist theory succeeded in taking root and spreading widely in China.

Guo Moruo believes that whether it is to study the history of human society or the history of human development, the focus should be on the living existence and the development ability of human beings with life activities in real life, espe- 
cially on the degree of freedom that living individuals are able to enjoy in the real society. Therefore, when analyzing the process of the collapse of the slave system, he illustrated in detail the evolution of "Ge (an ancient Chinese tripod with hollow legs)" and the complication of "Shi (a social stratum in ancient China)", and pointed out that "the complex composition of Shi, the so-called robbers, the thief, and the flow of car sellers can all become Shi. That does mean that in the process of social change, the degree of slave emancipation is quite thorough". It points out that "In Jin, at the end of the Spring and Autumn Period, Shi was raised to the status only slightly below literati and officialdom (in ancient China), and above the industrial and commercials, civil servants in government office, and herdsmen. It is a very significant change, which means that the main producer of society-the commoner-level peasants who were powered by farmershad been liberated from the lowest slave status and become semi-free people" (Guo, 1984a). The main producer of society, the "general farmers", had been liberated from slavery and became semi-free men. This was the fundamental reason for the collapse of slavery and the establishment of feudalism. The relationship between freedom and the state here is just as Marx noted, Freedom consists in turning the state from an institution standing on top of society into an institution that completely obeys this society. Moreover, today, various forms of state, relatively free or unfree, also depend on the extent to which these state forms restrict the freedom of the state (Marx and Engels, 1972).

\section{The Law of Free Evolution of Human Beings in Real Social Relations}

Guo Moruo believed that "now that the main producers of society were liberated from the status of being slaves, slavery collapsed", that is, when farmers were liberated from the most inferior slave status and became semi-free men, slavery came to an end. Among them, its main role is to discover the use value and real value of "human" and promote the discovery of the right to freedom of life as "human". This is the initial awakening of "human". He pointed out that "the use value of human was subsequently discovered, and some of the captives were enslaved without massacre, so that men came to be ministers and women concubines and some of them were specialized in production. So, the society came to experience internal division. There were enslaved people engaged in production, and renters who were out of production; society naturally underwent qualitative changes and transformation from a primitive communal system to slavery". Taken into consideration the level of human emancipation, Guo Moruo pointed out that it was inappropriate to delineate the boundary between slave society and feudal society at the turn of the Qin and Han dynasties. That is to say, in the entire social relationship, slaves were no longer dependent on slave owners who had the power to sustain or deprive their lives, but they developed independently into individuals who held the initiative to own their own lives. However, if they wanted to survive and live, they must sell their own labor to obtain the necessi- 
ties of their own lives. At this time, the feudal lords or landlords purchased the labor rights of free farmers and obtained their means of livelihood through land or hereditary officials.

With the emergence of productive slaves, the slave owners realized that "people were worthy of use", and then the people could not only be granted, but also be bought and sold. And the price gradually increased. This can be seen an opportunity for social change. It was a small number of people who awakened as "human consciousness" and begun to fight for their own liberation and freedom. It was manifested in such a struggle between private and public to win over the people. This shows the key to a social change. The people were freed from the bondage of slavery under such an opportunity. After the emergence of a class of scholars, people were divided into four people-the so-called scholars, farmers, artisans and merchants, among which Shi (scholars) ranked in the first place. This was the basic level of bureaucracy in the later feudal society. But this phenomenon could not last long. When the social turmoil calmed down, the composition of scholars was gradually purified; the world created by workers and peasants was ruled by new aristocrats. Those landlords and tycoons of industry and commerce took the place of slave owners and monopolized the so-called "Shi", that is, the monopoly of administrative power. As a result, a new feudal order was formed. What did artisans and farmers get? Nothing. Now they were enslaved by an intangible chain rather than a tangible one (Guo, 1984b). In the end, with the awakening and liberation of the free consciousness of the new aristocracy, a new feudal social order was formed.

Guo Moruo criticized Confucianism, the eight schools of Confucianism, the old school of JixiaHuanglao, Zhuangzi, Xunzi, the discernment of thought, early legalists, and Hanfeizi. He also criticized the awakening of human self-liberation, its external manifestation being whether it illuminated people's wisdom and stood in the aspect of representing people's interests. He said, "Fraud is the theory that Taoism itself should have. Because it is based on the standpoint of individualism. No matter what kind of individualism, a person cannot survive completely without the state and society, so it is easy to reveal its individualism in the principles of the state and society. Individualism that is not based on the people will inevitably develop into this. A further step is to deny the utility of all cultures and go backwards. But he rejected it. What is it? Only it is the sagacious wisdom of the people; the end of knowledge is "the extension of knowledge". And as soon as the time comes, it becomes "all things are in my possession" ("Mencius"); therefore, "it is sincere and joyful." At this time, it is what "The Doctrine of the Mean" said, "Those who can do their best, can do their best." The four principles in terms of improving oneself and bring harmony into ones household before achieving better management of the state are clearly deduced by Mencius, for he once said The foundation of the world lies in the country; the foundation of the country is at home, and the foundation of the home is in the body ("Li Lou Shang"). This is the foundation of self-cultivation, equipping the 
family, governing the country, and pacifying the world. "Yao Dian" praises Tang Yao's holy virtue that also contains these stages. Educate the people and bring their customs into fashion, so people nearby are happy to follow them, and those who are far away cherish it by the same token. It is a matter of aligning the family, ruling the country, and pacifying the world. Guo Moruo criticized the old culture and established a new system based on the level of self-liberation. $\mathrm{He}$ pointed out that the people were the production of slaves. This is an important thing I discovered in ancient society, but in fact, this is already a kind of progress. The people did not even have the status of slaves before reaching this historical stage. History is the whole, and individual social relations also depend on the entire social relations to determine (Guo, 1984b). Then a whole chapter is used to discuss the evolution of the people's identity.

\section{The Relationship between Human Development and the Development of Human Society}

Marx pointed out that human beings have experienced three major historical forms of development. Human dependence is the initial social form. Under this form, human production capacity only develops in a narrow range and in an isolated location. Human independence based on the dependence of things is the second largest form. Only in this form can a system of universal social material exchange and comprehensive relationships, multi-faceted needs and capabilities come into shape. Free personality based on the overall development of individuals and their common social productive capacity becomes their social wealth. This is the third stage. The second stage creates conditions for the third stage" (Marx, 1962).

The first stage of human development is the "natural person" stage. In primitive society, there is no dependence of one part of people on another. All people must be totally dependent on nature as a whole. This is the primary stage of human development-the natural person stage. This is due to low productivity and a serious shortage of daily necessities. Although everyone is free, the consciousness of being "human" had not been awakened. In order to survive, one could only implement a clan system without masters and slaves. A clan was a family. But this "was a great improvement in ideology, treating the people as equal sons of heaven." Clansmen in a state of ignorance had no distinction between high and low. They were all sons of nature. They were in the initial stage of human development and were not free.

The second stage of human development is the "social man stage". A total of three social forms, namely slave society, feudal society, and capitalist society (socialist society), are characterized by the fact that in the real society, there are some people who depend on the other. In the slave society, under the premise of dependence on nature, some people in society had a dependent relationship with some other people; in feudal society, under the premise of dependence on nature, some people in the society were not dependent on others. The prerequisite 
was the human body, but was replaced by things outside the body, such as land, officials, etc.; However, in a capitalist society some people in a society no longer have a dependent relationship with other people, but the whole society has nothing. Without exception, it is attached to an unnatural outsider: capital. The common feature of slave society, feudal society, and capitalist society is the rule of people. This rule is caused by the lack of productivity and the inadequacy of social wealth. Controlling the person, the means of production and living, and capital are undoubtedly part of the tools owned by the ruling class. Only by knowing this can we understand that the "social man stage" is only the freedom of a few people, at this time, the consciousness of people as people gradually awakens and develops rapidly. In the primary stage of socialist society, people in the whole society are no longer attached to an unnatural external object-capital, but become interdependent objects with each other. They begin to explore the mode of harmonious coexistence between people and nature, people and society, people and people. With the continuous development of social stage, the degree of harmonious coexistence continues to improve, and harmonious coexistence gradually internalizes into people self-development is a kind of subconscious. Entering the advanced stage of socialist society and developing into the freedom of the majority of people, people's consciousness of being human is mature. Finally, man and nature reach a complete reconciliation and enter the third stage of human development.

The third stage of human development is the "free man stage", which starts from entering the communist society. In the real society, people and people, people and society, and people and nature are completely reconciled. This means that material and spiritual wealth will be extremely abundant, and everyone's abilities will be fully and freely developed. Because the wealth of society is extremely rich, people's consciousness as a person will be fully awakened, everyone's abilities will be fully developed, and everyone will become the master of freedom, so they are called "free people." In this state of society, there will be no more classes, no more exploitation, and no more countries. As Marx said: "At that time, the domination of people will be replaced by the management of things and the leadership of the production process. The state will not be abolished, it will perish on its own" (Marx and Engels, 1972). A communist society will achieve complete reconciliation between humans and society, and between humans and nature in reality so that individuals living in reality can truly achieve the realm of "following their hearts".

Marx divides the development of human history into a syllogism of selfdevelopment and a five-stage theory of social development, both of which are the internal and external manifestations of the same process of human development history. In this regard, Guo Moruo's historical thoughts point to the development process of human history with his focuson the level of awakening of conscious individuals as "humans" in real social relations, so that men can ultimately realize the ideal of leading a free life "as one wishes". 


\section{Conflicts of Interest}

The author declares no conflicts of interest regarding the publication of this paper.

\section{References}

Guo, M. R. (1984a). Collected Works of Guo Muoruo (Vol. 3). Beijing: People's Publishing House.

Guo, M. R. (1984b). Collected Works of Guo Muoruo (Vol. 2). Beijing: People's Publishing House.

Marx, C. (1962). A Critique of Political Economy. Beijing: People's Publishing House.

Marx, C., \& Engels, F. (1972). Collected Works of Marx and Engels (Vol. 3). Shanghai: People's Publishing House. 